\title{
LABORATORY INVESTIGATION OF A NEW LIBYAN CHEMICAL EOR: Impact of GWLI on Relative Permeability, Wettability, Oil Recovery, Breakthrough and Fractional Flow
}

\author{
M A Naser ${ }^{1}$, O Azuza ${ }^{2}$ \\ ${ }^{1}$ Department of Petroleum Engineering, Misurata University, Libya \\ Albeera District, The City of Misurata, Libya, P.O Box 2478 \\ ${ }^{2}$ Department of Industrial Engineering and Manufacturing, Misurata University, Libya \\ Albeera District, The City of Misurata, Libya, P.O Box 2478 \\ Corresponding Author: madinaser2004@gmail.com
}

\begin{tabular}{|c|c|}
\hline Article History: & Abstract \\
\hline $\begin{array}{l}\text { Received: October 15, } 2018 \\
\text { Receive in Revised Form: April 16, } 2019 \\
\text { Accepted: April 17, } 2019\end{array}$ & \multirow[b]{3}{*}{$\begin{array}{l}\text { The greater demand for crude oil, the increased difficulty of } \\
\text { discovering new reservoirs, and the desire to reduce dependence on } \\
\text { imports have emphasized the need for enhanced recovery methods } \\
\text { capable of economically producing the crude remaining in known } \\
\text { reservoirs. Oil recovery from oil reservoirs may be improved by } \\
\text { designing the composition and salinity of water injection. The } \\
\text { process is sometimes referred to as sea or smart water injection. In } \\
\text { this paper, a Gaberoun Water Leak Injection (GWLI) have been } \\
\text { discovered and investigated as a new Libyan chemical EOR in } \\
\text { laboratories on relative permeability, wettability, oil recovery, } \\
\text { breakthrough, and fractional flow for carbonate and sandstone } \\
\text { reservoirs. GWLI has several advantages which are relatively cheap, } \\
\text { reliable, and available. GWLI potentially would have a wide range } \\
\text { of applications in water injection such as wettability alteration. The } \\
\text { equipment and the operating procedures were designed to simulate } \\
\text { the reservoir condition. The experimental results indicate that, that } \\
\text { the GWLI has caused the increasing of oil recovery in sandstone and } \\
\text { carbonate core. The impact of GWLI on oil recovery in sandstone } \\
\text { core samples was higher than carbonate core samples. The effect of } \\
\text { acidity (pH) of GWLI on oil recovery in sandstone and carbonate } \\
\text { core samples was higher when the pH is } 5 \text { than when the acidity is } \\
\text { 10. Hopefully, the research findings can possibly be useful for } \\
\text { references and for operating companies as an important source for } \\
\text { understanding and visualizing the effects of pH, permeability, } \\
\text { porosity, and wettability on oil recovery in reservoir rock using } \\
\text { GWLI. }\end{array}$} \\
\hline Keywords: & \\
\hline $\begin{array}{l}\text { Relative permeability, Wettability, Recovery } \\
\text { factor, Breakthrough, Fractional flow, } \\
\text { GWLI }\end{array}$ & \\
\hline
\end{tabular}

\section{INTRODUCTION}

Although, the primary recovery is the first stage of petroleum and gas production, the secondary oil recovery involves the injection of gas or water, which will displace the oil, force it to move from its resting place and bring it to the surface. Rather than simply trying to force the oil out of the ground, as did the previous two methods, enhanced oil recovery seeks to alter its properties to make it more conducive to extraction by using some form of additional engineering technique (Sheng, 2011). For example, water injection involves drilling injection wells into a reservoir and introducing water into that reservoir to encourage oil production (Schiozer \& Mezzomo, 2003). While the injected water helps to increase depleted pressure within the reservoir (Baruah \& Chan, 2014; Martinez \& Ascendo, 2018; Siso, Awni, Solyman, \& Ibrahim, 2017), it also helps to move the oil in place. The water used for water injection is usually some sort of brine, but it can also be made up of other sources that are treated (McCune, 1982). Modifying 


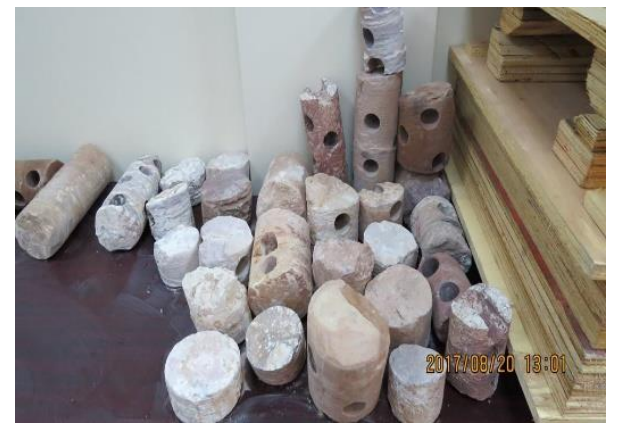

Journal of Earth Energy Engineering Vol. 8 No. 2, October 2019, pp 55-66

Figure 1. Sandstone and carbonate cores that used for this study

water salinity to increase oil recovery is a relatively new method that could be applied in many oil fields to unlock millions of barrels of oil (Hidayat, Erfando, \& Maulana, 2018; Ramanathan, Shehata, \& NasrEl-Din, 2015). Seawater and saline aquifers are typical sources of water in conventional water injection projects. Several studies, supported by field tests, suggest that additional oil can be recovered by reducing salinity and/or adding some key ions to the water salts (Banks et al., 2015; Ngansom \& Dürrast, 2016).

Oil reservoirs are classified into sandstones and carbonates and each has relatively different properties and characteristics (A. M. Shehata, Alotaibi, \& Nasr-El-Din, 2014; Sheng, 2011). Modifying water salinity could impact oil recovery in both types, although the mechanism and approach could be different. It has been reported that the ionic strength of injection water can have a major impact on the recovery of hydrocarbons during water-floods, with increased recovery resulting from the use of low salinity brines in sandstone reservoirs (Alotaibi, Nasralla, \& Nasr-El-Din, 2011). Both laboratory and single well field tests have documented that enhanced oil recovery can be obtained from sandstone reservoirs by performing a tertiary low saline water-flood (Austad, Rezaeidoust, \& Puntervold, 2010). The reservoir connate water composition had a dominant influence on the oil-recovery rate. The changes in the cation composition of reservoir connate water $\left(\mathrm{Ca}^{2+}, \mathrm{Mg}^{2+}\right.$, and $\left.\mathrm{Na}^{+}\right)$showed a measurable change in the oil-production trend. Reservoir cores saturated with $\mathrm{CW}$ containing divalent cations of $\mathrm{Ca}^{+2}$ and $\mathrm{Mg}^{+2}$ showed higher oil recovery than cores saturated with monovalent cations $\left(\mathrm{Na}^{+}\right)$(Hidayat et al., 2018; Ahmed M. Shehata \& Nasr-El-din, 2017). Low salinity water-flooding, versus high salinity water-flooding has been the focus of significant research at various centers around the world, yet there is still considerable debate over the exact mechanism that provides incremental oil recovery (Law, Sutcliffe, \& Fellows, 2014). The impact of water salinity on oil recovery is different in carbonates as compared to sandstones (Al-Shalabi, Sepehrnoori, Delshad, \& Pope, 2015). Oil recovery from carbonate rocks is usually low due to the complex heterogeneity and the wettability state ranging from mixed-wet to oil-wet. Low salinity water injection is one of the emerging improved oil recovery techniques for boosting the oil recovery from water-floods (AlShalabi, Sepehrnoori, Delshad, et al., 2015). The improvement in oil recovery by Low salinity water injection in carbonates also depends on temperature, pressure, mineralogy, oil type, initial rock wettability state, and injected water composition, so the results in other carbonates might vary (Al-Shalabi, Sepehrnoori, \& Pope, 2015; Naser, 2016). Adding divalent ions such as calcium and magnesium along with sulfate at elevated temperature could increase oil production. The release of oil is attributed to ionic interactions between oil, water and rock surface that eventually lead to oil detachment from the rock surface (Austad, Strand, Madland, Puntervold, \& Korsnes, 2008). Previous experiments results show that injection of low salinity brine into carbonate reservoirs has potential as an EOR technology (Romanuka et al., 2012).

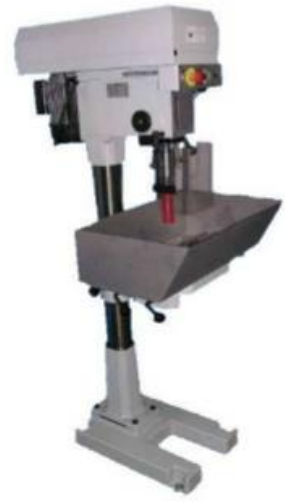

Figure 2. Plugging machine

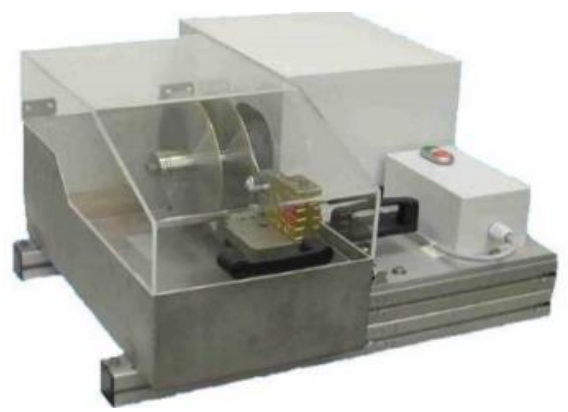

Figure 3. Trimming saw 


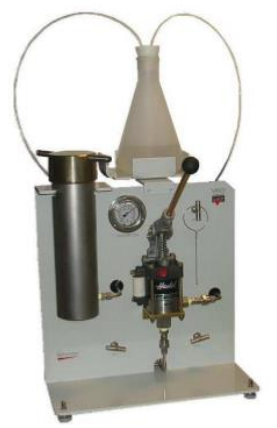

Figure 4. Manual saturator

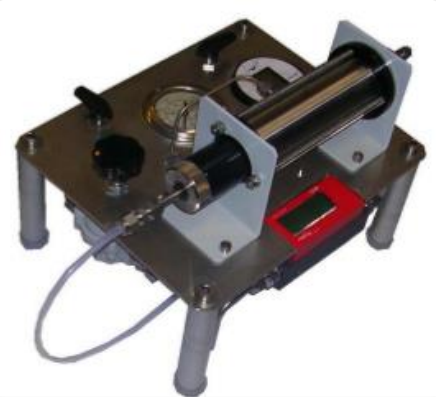

Figure 6. Gas Permeameter

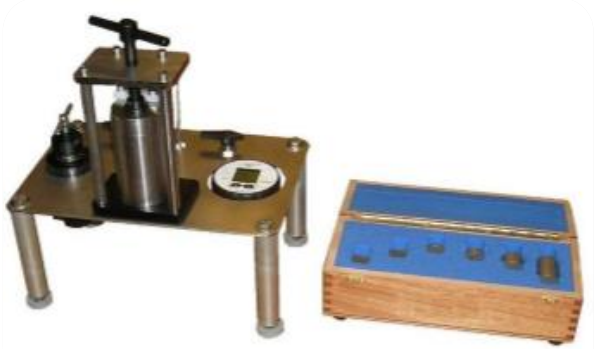

Figure 5. Helium porosimeter

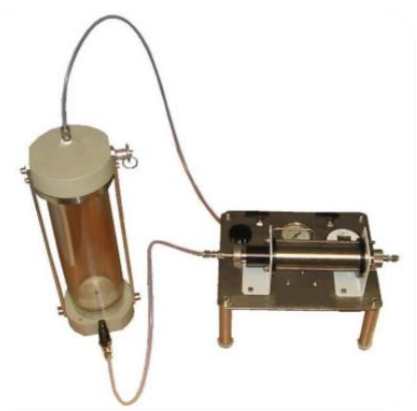

Figure 7. Liquid Permeameter

Previous work has focused on demonstrating the effect of modified brine formulation on particular carbonate and sandstone samples. It also demonstrates that water salinity is an important aspect of EOR applications (such as a water injection process) and it plays an important role in the success or failure of the project. Modifying the chemistry of injection water yields improved oil recovery on carbonate and sandstone rock surfaces. This research has been conducted for almost two years to understand the processes of Gaberoun Water Lake Injection (GWLI) and their effects on relative permeability, wettability, oil recovery, breakthrough and fractional flow for carbonate and sandstone reservoirs.

\section{MATERIALS AND METHODOLOGY}

Materials that used in this experiment are included:

1. Core Samples: Figure 1 shows the sandstone and carbonate cores. All of these cores were taken from the X - field.

2. Oil Sample: Oil with a density of $0.80266 \mathrm{~g} / \mathrm{cc}$ has been used in this study.

3. GWLI: GWLI is from Gaberoun Lake in Awbari desert, Libya.

4. Acetic acid glacial $\mathrm{CH}_{3}$. $\mathrm{COOH}$ (GRP): GRP has been used in this study to decrease the potential of hydrogen of GWLI.

Experimental equipments used in this experiment are included:

1. Plugging Machine: Before the main experiment of this study could start, cores had to be cut in regular size. To obtain different shapes of core sample, we have set up cutting machine with a diamond rib as shown in figure 2.

2. Trimming Saw: Bench top tool designed to cut preset core sample lengths as shown in the figure 3.

3. Stable Temp Vacuum Oven: The air forced drying oven enables efficient drying of core samples after cleaning with solvents before permeability or porosity measurements.

4. Manual Saturator: Manual saturator permits to perform a sequence of vacuum and saturation cycles on plug size samples as shown in the figure 4.

5. Digital Balances: Digital balances, especially selected for core applications where measurement accuracy is required.

6. Helium Porosimeter: Helium gas expansion porosimeter is used for direct grain volume and pore volume measurement as shown in the figure 5. Subsequently, porosity and grain density can be derived from the direct measurements. 
7. Steady State Gas Perm meter: Gas Perm instrument is dedicated to measure permeability to gas of plug sized core samples at room conditions and reservoir overburden pressure using the steady state method as shown in the figure 6.

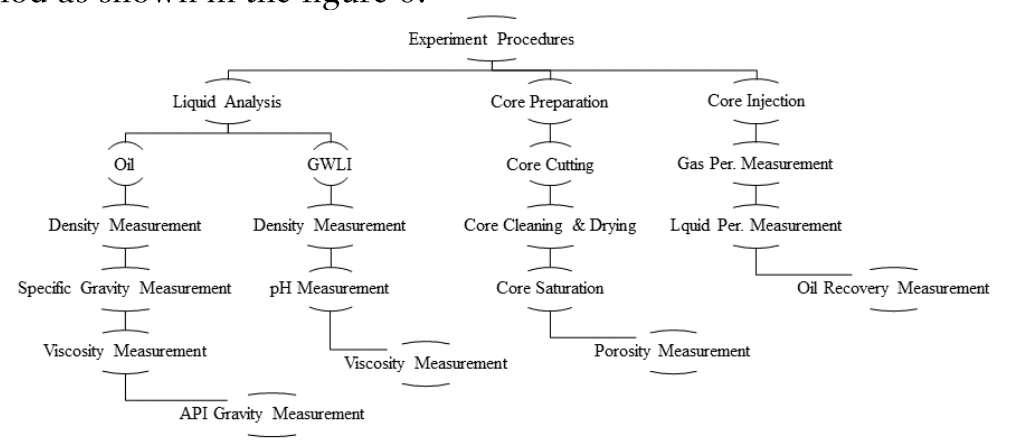

Figure 8. Experimental flow chart procedures

8. Liquid Perm meter: Liquid permeameter is dedicated to measure permeability to liquid of plug sized core samples at room conditions as shown in the figure 7.

9. Caliper: Caliper is used to measure the distance between two opposite sides of the core sample to measure the bulk volume of the core sample.

10. TubeTest: It is used to measure the volume of the oil and water extracted from the core sample.

11. Volumetric Flask $100 \mathrm{ml}$ : Flask is to use to measure the volume of the oil to measure the density of oil.

12. Marsh Funnel: Marsh funnel is a simple device for measuring viscosity by observing the time it takes a known volume of liquid to flow from a cone through a short tube.

13. Thermo Meter: Meter is used to know the room temperature to measure specific gravity of oil.

14. Jenway 3505 PH meter: Meter is used to measure $\mathrm{pH}$ of water.

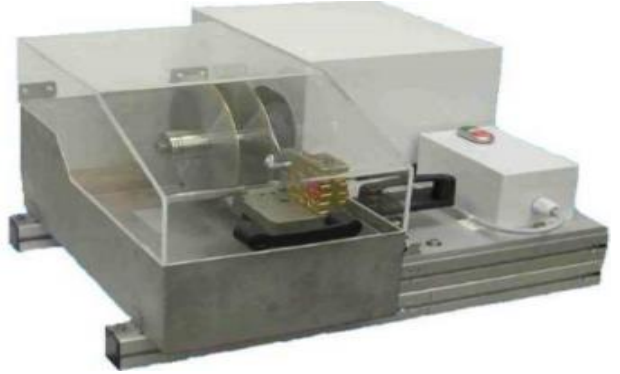

Figure 10. Trimming device used for trimming the core sample

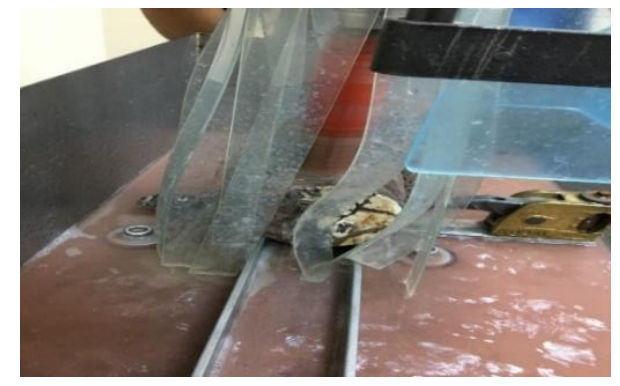

Figure 9. The sample in plugging machine during drilling process

\section{EXPERIMENT PROCEDURES}

The following three steps are used in the procedure for preparing and doing experiment. They are shown in the Figure 8 and described in detail as follows:
Liquid Analysis:
i. GWLI density measurement.
ii. GWLI pH measurement.
iii. GWLI viscosity measurement.
iv. Oil density measurement.
v. Oil specific gravity measurement.
vi. Oil API gravity measurement.
vii. Oil viscosity measurement.

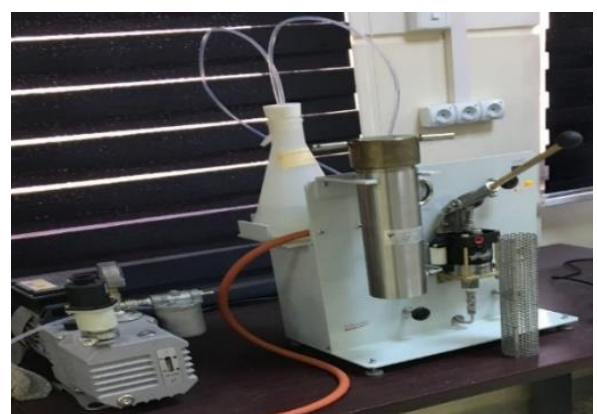

Figure 11. Saturation device used to saturate core sample

\section{Core Preparation:}

i. Cutting and Trimming the Core: Use the core plug machine to plug the sample as shows in the Figure 9. Use the core trimming device to trim the core sample after plugging by plug machine as shows in the Figure 10. The core sample has been plugged and trimming. 
ii. Core Saturation: By using the manual saturation device for saturation the core sample as shows in Figure 11. Put the core plug in the core cell chamber sample and measure the weight of the dry core sample. Turn the valve no. 1 between the vacuum pump and core sample container and close the valve no. 2 between the core sample container and the brine reservoir. Then, turn on the vacuum pump until the vacuum pressure is stable, then, wait for 2 minute and then turn off the vacuum pump. After that, open the valve no. 2 to allow the brine to flow to the core sample container. Once the liquid level in the saturated vacuum tank is stable, then turn off the valve no. 2 and vacuum pump. Start to pressurize the core chamber cell manually and slowly up to 2,000 psi. Then, monitor and keep the pressure on 2,000 psi till it stabilize. After that, waited for 24 hours, then open the valve no. 2 and then, wait the pressure gauge back to zero. Slightly, take out the core sample and wipe out the liquid on the sample surface by rolling it on a piece of paper. Measure and record the weight of the saturated core sample.

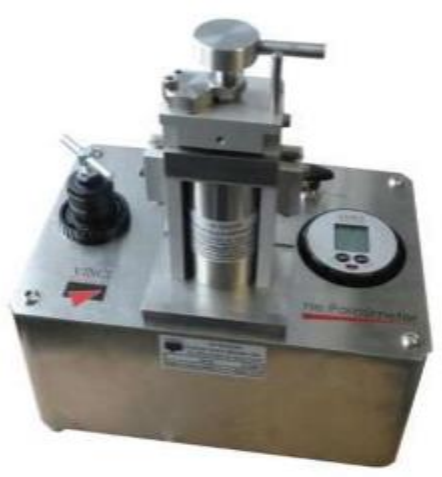

Figure 12. Helium porosimeter used to measure the porosity

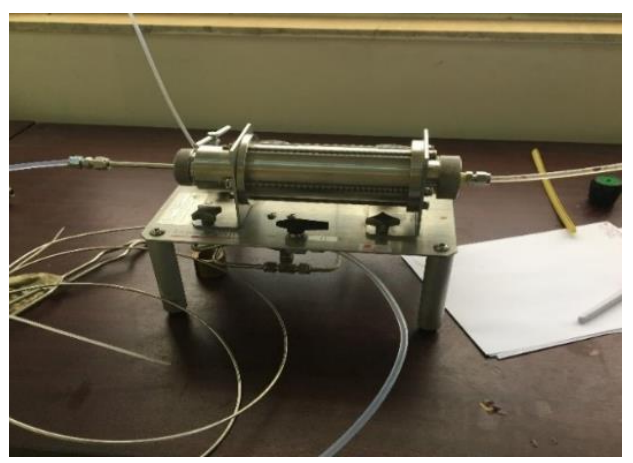

Figure 14 Liquid device used to measure liquid permeability

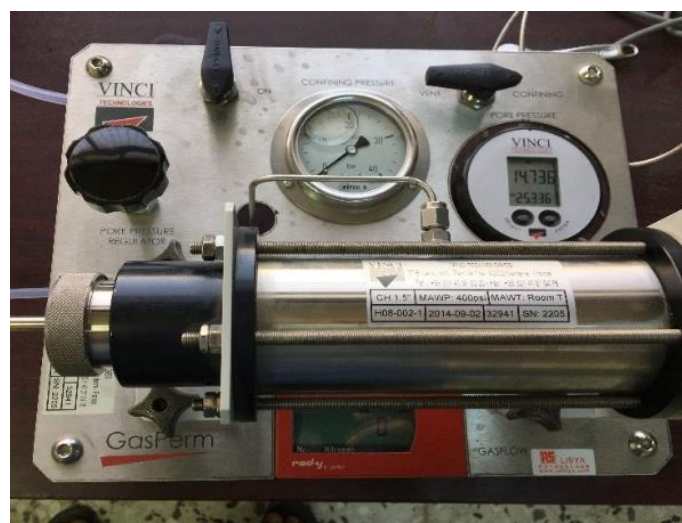

Figure 13. Gas permeability device used to measure gas permeability

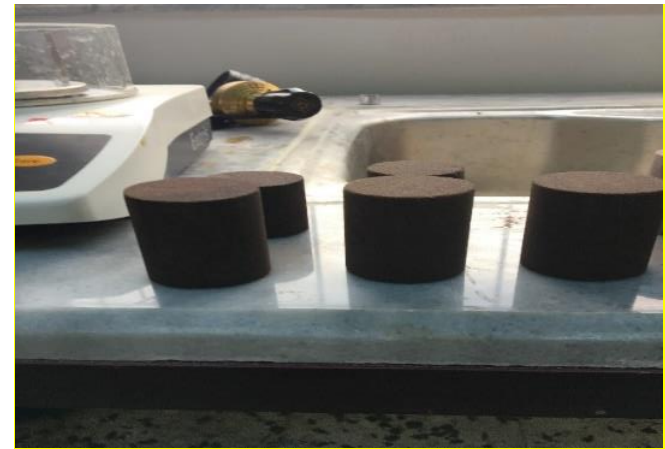

Figure 15 Core sample after saturated oil and water

iii. Porosity Measurement: Helium gas expansion porosimeter enables the determination of a sample's (1" or 1.5" diameter) grain and pore volume via an isothermal helium expansion and the application of Boyle's law and Charles' law. Subsequently, porosity and grain density can be calculated. Use helium porosimeter to measure porosity of the core sample as shows in the Figure 12. Put the core in the core holder and close it. Open the valve no. 1 to allow the pressure to enter to the core holder. Read the pressure on the pressure console. Switch on the valve the expansion to allow the gas to enter to the core. Read the pressure on the pressure console. Compute the grain volume of the core sample may expressed by Equations (1):

$\mathrm{V}_{\text {grain }}=\left(\mathrm{V}_{\text {mat }}-\mathrm{V}_{\text {ref }}\right)-\left(\mathrm{P}_{\text {ref }} / \mathrm{P}_{\text {exp }}\right) * \mathrm{~V}_{\text {ref }}$

Compute the pore volume of the core sample may expressed by Equations (2):

$P_{V}=B_{v}-V_{g}$ 
Compute the porosity of the core sample by the Boyle's may expressed by Equations (3):

$\varnothing=\mathrm{P}_{\mathrm{v}} / \mathrm{B}_{\mathrm{v}}$

\section{Core Injection:}

Gas Permeability Measurement: The measurement of gas permeability is divided form Darcy Law, under steady state condition of viscous or laminar flow may expressed by Equations (4) and (5):

$\mathrm{Kg}=\frac{Q b * \mu * L * P b}{A * \Delta P * P m}$

$\mathrm{P}_{\mathrm{m}}=\frac{p 1+p 2}{2}$

i. Use the gas permeability device to measure the permeability of core as showing in the Figure 13. Put the core sample into the core holder and switch on the confining valve confining pressure to confine on the core. After that, switch on the anther valve to allow the gas to enter to core. Then, read the gas flow rate on the flow console and the pressure. After that, compute the gas permeability of the core sample from Darcy law.

ii. Liquid Permeability Measurement: The measurement of liquid permeability is divided form Darcy Law which for liquid, under steady state condition of viscous or laminar flow may expressed by Equations (6):

iii. $\quad \mathrm{K}=\frac{Q \mu L}{A \Delta P}$

iv. Use the liquid perm device to measure the permeability of core as showing in Figure 14. Put the core sample into the core holder and switch on the confining valve confining pressure to confine on the core. After that, edit the regulator to setting the input pressure the pressure on the water to enter to the core sample. Then, open the valve to allow the pressure on the water. After that, open the tank valve to enter the water to the core holder then into the core sample. After some time, the water will exit form the core. Then, compute the volume of the water and the time. After that, compute the flow rate by the flow rate expressed by Equations (7):

v. $Q=V / T$

vi. Compute the liquid permeability from Darcy Law for liquid.

GWLI: The core flooding experiment

i. Absolute permeability measurement by inject the brine into the core sample when it's saturated $100 \%$ by the brine. Use the manual saturation device to saturate the core with $100 \%$ of brine and measure the weight of the saturated core sample.

ii. Then, put the core sample in liquid perm device to measure absolute permeability.

iii. Oil injection to irreducible water saturation $\left(\mathrm{s}_{\mathrm{wi}}\right)$ and measure the effective permeability of oil $\left(\mathrm{k}_{\mathrm{eo}}\right)$.

iv. After that, measure absolute permeability of core by inject the oil into the core until the brine out and the oil arrive to $s_{\mathrm{wi}}$ as showing in Figure 14.

v. GWLI injection to displacement the oil into the residual oil saturation $\left(s_{\mathrm{or}}\right)$, and then measure the effective permeability of water at $s_{0 r}$.

vi. GWLI begin injected in the core sample and measure the volume of oil with time before water breakthrough.

vii. During GWLI, the breakthrough is happened, then measure the volume of oil and water with time.

viii. At the end, only water is produced at $\mathrm{s}_{\mathrm{or}}$ (residual oil saturation).

ix. Compute the relative permeability by Corey model.

$x$. Compute the fractional flow by Buckley-Leverett Analysis.

\section{EXPERIMENTAL RESULTS}

\section{A. GWLI and Oil Analysis Results}

Table 1 shows the comparison between densities of GWLI and Distilled Water at room condition. Table 2 shows the oil density, oil density, Specific gravity, API gravity, and oil viscosity results at room conditions. 
Table 1 Density, Viscosity, and pH of GWLI and Distilled Water results

\begin{tabular}{llll}
\hline Type & Density $(\mathrm{g} / \mathrm{cc})$ & Viscosity $(\mathrm{cp})$ & $\mathrm{pH}$ \\
\hline GWLI & 1.143 & 27 & 10.025 \\
Distilled Water & 0.995 & 0.990 & 7 \\
\hline
\end{tabular}

Table 2 Oil density, Sepcific Garvity, API Garvity, and Viscosity results.

\begin{tabular}{lllllll}
\hline Oil Name & $\begin{array}{l}\text { Temperature } \\
\left({ }^{\circ} \mathbf{C}\right)\end{array}$ & $\begin{array}{l}\text { Oil density } \\
\boldsymbol{\rho}_{\mathrm{o}}(\mathbf{g} / \mathrm{cc})\end{array}$ & $\begin{array}{l}\text { Specific gravity } \\
\boldsymbol{\gamma}_{\mathrm{o}}\end{array}$ & API gravity & API Degree & Viscosity (cp) \\
\hline Hamada oil & 31.4 & 0.803 & 0.807 & $43.84^{\circ}$ & Light oil & 4.013 \\
\hline
\end{tabular}

\section{B. Core Analysis Result}

Table 3 shows the porosity of carbonate and sandstone cores sample. By divided the pore volume on bulk volume of carbonate and sandstone cores sample, the porosity was obtained. The results shows that, the highest porosity value of carbonate core samples $(\mathrm{C}-005)$ is $43 \%$, and the lower porosity value $(\mathrm{C}-004)$ is to $24 \%$. The results shows that, the highest porosity value of sandstone core samples (S-106) is $47 \%$, and the lower porosity value (S-602) is $27 \%$. Table 4 shows the liquid and gas permeability of carbonate and sandstone core samples results by using liquid permeability device.

Table 3 Porosity of carbonate and sandestone cores sample

\begin{tabular}{llll}
\hline Core No & Porosity Value $\mathbf{( \% )}$ & Core No & Porosity Value $\mathbf{\%})$ \\
\hline C-001 & 37.13 & S-203 & 34.72 \\
C-002 & 26.61 & S-300 & 38.84 \\
C-003 & 41.66 & S-301 & 38.73 \\
C-004 & 24.19 & S-302 & 37.38 \\
C-005 & 43.28 & S-400 & 34.81 \\
S-100 & 39.96 & S-401 & 38.97 \\
S-101 & 42.34 & S-402 & 34.51 \\
S-102 & 37.88 & S-403 & 37.09 \\
S-103 & 36.63 & S-404 & 37.38 \\
S-104 & 40.94 & S-500 & 38.17 \\
S-105 & 41.41 & S-501 & 35.98 \\
S-106 & 47.36 & S-600 & 34.19 \\
S-107 & 40.18 & S-601 & 40.24 \\
S-108 & 40.05 & S-602 & 27.11 \\
S-200 & 39.48 & S-603 & 38.72 \\
S-201 & 36.28 & S-604 & 35.44 \\
S-202 & 36.12 & Note: C-Carbonate Core & Note: S-Sandstone Core \\
\hline
\end{tabular}

Table 4 Liquid and Gas permeability of carbonate core samples result

\begin{tabular}{lllllll}
\hline $\begin{array}{l}\text { Core } \\
\text { No }\end{array}$ & $\begin{array}{l}\text { Gas } \\
\text { Permeability } \\
\text { (d) }\end{array}$ & $\begin{array}{l}\text { Liquid } \\
\text { Permeability } \\
\text { (d) }\end{array}$ & $\begin{array}{l}\text { Core } \\
\text { No }\end{array}$ & $\begin{array}{l}\text { Gas Permeability } \\
\text { (d) }\end{array}$ & $\begin{array}{l}\text { Liquid } \\
\text { (d) }\end{array}$ & Permeability \\
C-001 & 7.97 & 0.041 & S-203 & 311.40 & 2.31 \\
C-002 & 0.09 & - & S-300 & 153.60 & 0.78 \\
C-003 & 7.11 & - & S-301 & 363.04 & 2.32 \\
C-004 & 0.05 & - & S-302 & 256.17 & 1.80 \\
C-005 & 42.25 & 0.13 & S-400 & 116.75 & 0.97 \\
\hline
\end{tabular}




\begin{tabular}{llllll}
\hline S-100 & 238.09 & 2.59 & S-401 & 138.33 & 0.63 \\
S-101 & 331.58 & 1.11 & S-402 & 206.87 & 1.94 \\
S-102 & 134.18 & 2.46 & S-403 & 71.21 & 0.29 \\
S-103 & 162.24 & 1.44 & S-404 & 276.53 & 2.06 \\
S-104 & 272.97 & 2.25 & S-500 & 345.37 & 3.27 \\
S-105 & 392.40 & 3.60 & S-501 & 128.31 & 1.00 \\
S-106 & 1006.49 & 4.43 & S-600 & 204.20 & 1.01 \\
S-107 & 244.24 & 1.36 & S-601 & 315.24 & 1.97 \\
S-108 & 225.95 & 1.28 & S-602 & 4.60 & 0.03 \\
S-200 & 127.95 & 0.96 & S-603 & 367.67 & 1.36 \\
S-201 & 89.84 & 0.53 & S-604 & 137.07 & 0.78 \\
S-202 & 99.87 & 0.97 & Note: & C Core & Carbonate \\
\hline
\end{tabular}

\section{Core Flooding Result}

Figures 16 and 17 show the relative permeability and fractional flow for S-101 core sample by GWLI. According to the relative permeability curve from the intersection point, the wettability of this core is water-wet. From figure 18, the actual water saturation breakthrough is $68.072 \%$ and the breakthrough occurs when the water saturation at breakthrough $S_{\mathrm{wbt}}=0.55$ and the fractional flow at breakthrough $\mathrm{f}_{\mathrm{wbt}}$ $=0.75$. Both of figures 19 and 20 show the relative permeability and fractional flow for S-400 core sample by GWLI. Based on the intersection point in the relative permeability curve, the wettability of this core is water wet. From figure 20, the actual water saturation breakthrough is $60.09 \%$, and the breakthrough occurs when the water saturation at breakthrough $S_{\mathrm{wbt}}=0.50$ and the fractional flow at breakthrough $\mathrm{f}_{\mathrm{wbt}}$ $=0.75$.

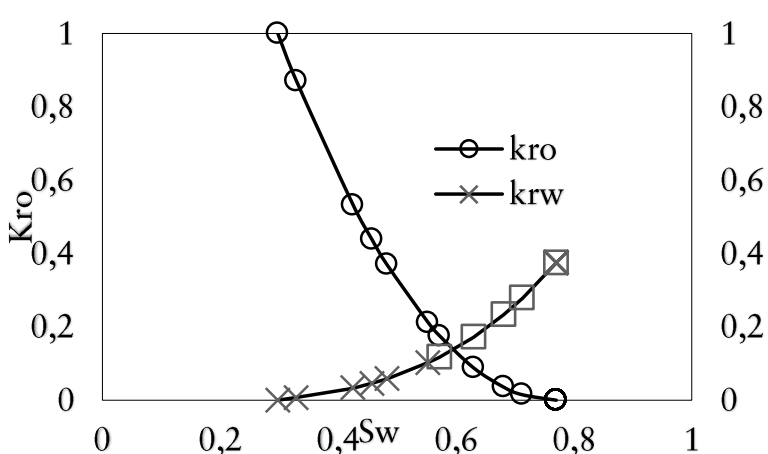

Figure 17 Relative permeability curve for S-101 core

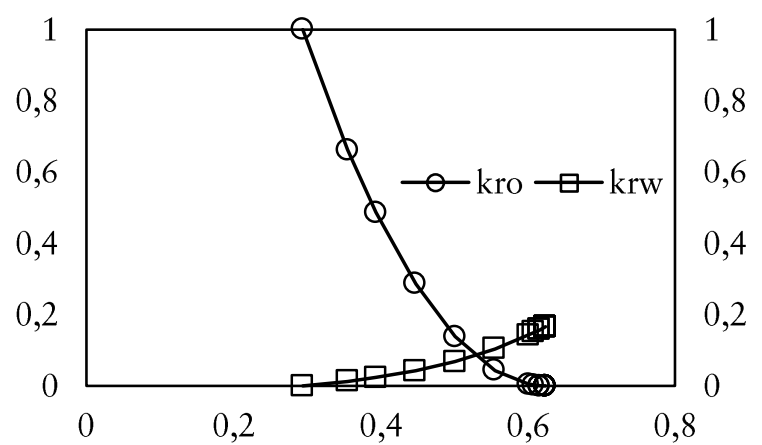

Figure 19 Relative permeability curve for S-400 core

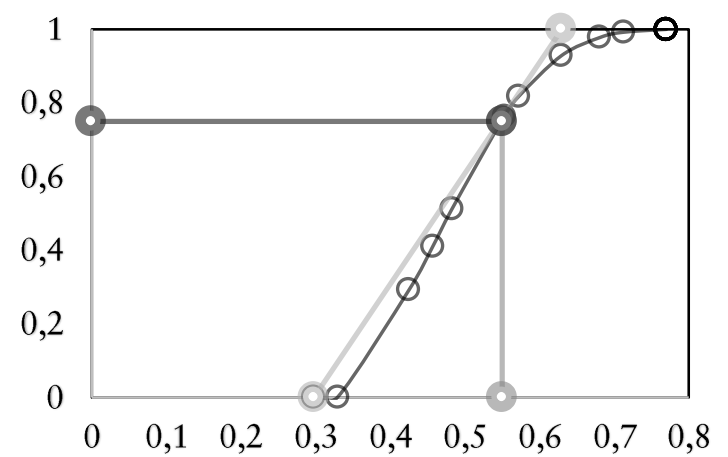

Figure 18 Fractional flow curve for S-101 core

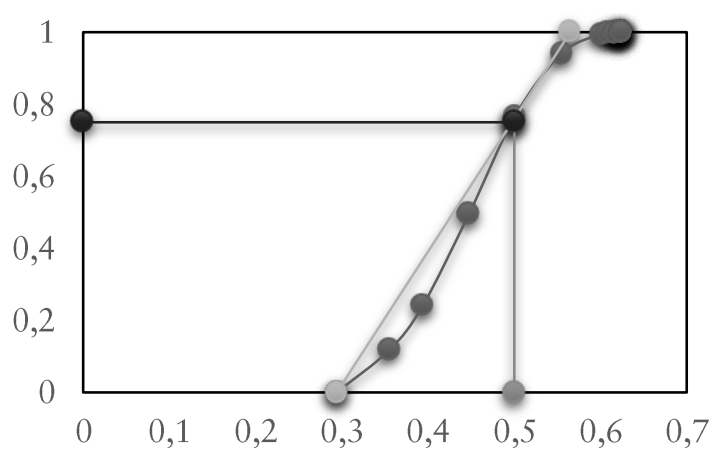

Figure 16 Fractional flow curve for S-101 core 


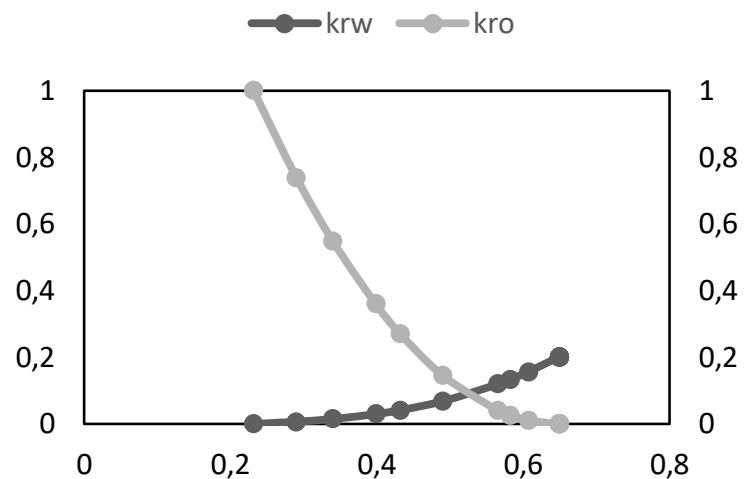

Figure 20 relative permeability for S-600 core sample

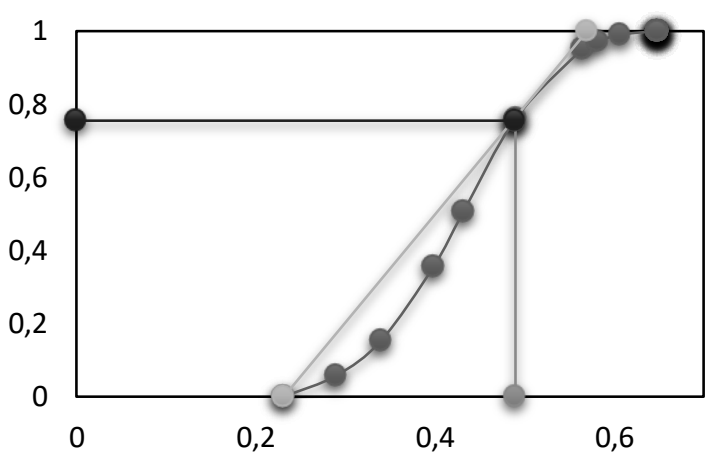

Figure 21 Fractional flow for S-600 core sample

Figures 20 and 21 show the relative permeability and fractional flow for S-600 core sample by GWLI. According to the relative permeability curve from intersection point curves, the wettability of S-600 is water wet. From figure 21, the actual water saturation breakthrough is $58.23 \%$, and the breakthrough occurs when the water saturation at breakthrough $S_{w b t}=0.49$ and the fractional flow at breakthrough $\mathrm{f}_{\mathrm{wbt}}$ $=0.755$. Figures 22 and 23 show the relative permeability and fractional flow for S- 601 core sample by GWLI. According to the relative permeability curve from intersection point curves, the wettability of S601 is mixed wet. From figure 23, the actual water saturation breakthrough is $38.21 \%$, and the breakthrough occurs when the water saturation at breakthrough $S_{w b t}=0.485$ and the fractional flow at breakthrough $\mathrm{f}_{\mathrm{wbt}}=0.77$.

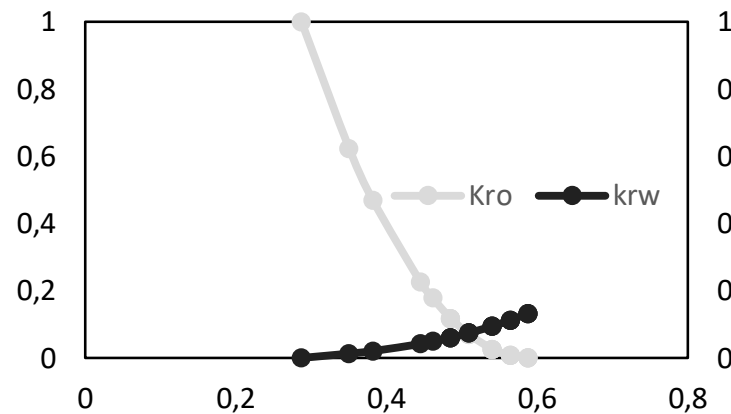

Figure 22 Relative permeability for S-601 core sample

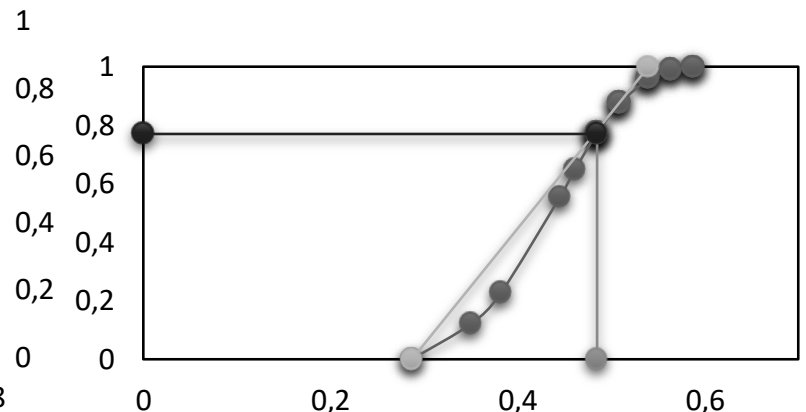

Figure 23 Fractional flow for S-601 core sample

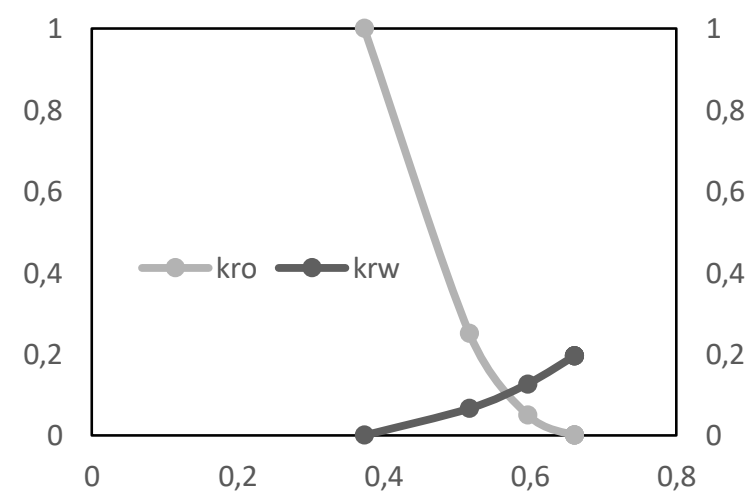

Figure 24 Relative permeability for S-603 core sample

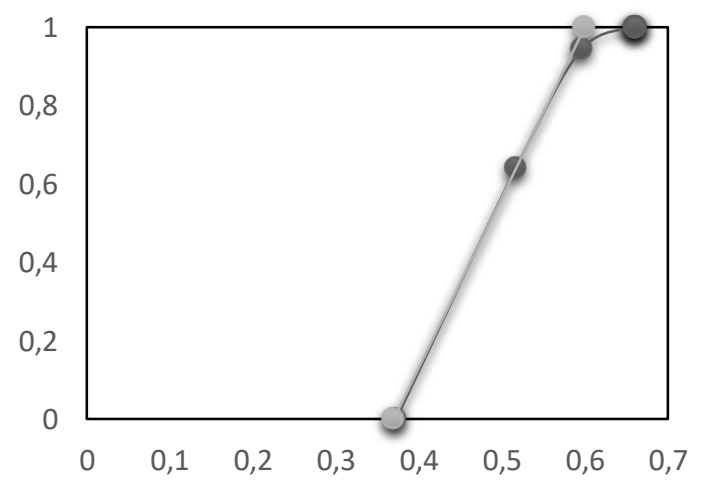

Figure 25 Fractional flow for S-603 core sample 
Figures 24 and 25 show the relative permeability and fractional flow for S-603 core sample by GWLI. According to the relative permeability curve from intersection point curves, the wettability of this core sample is water wet. From figure 25, the actual water saturation breakthrough is $66.11 \%$, and the breakthrough occurs when the water saturation at breakthrough and the fractional flow at breakthrough occur in the beginning the GWLI. Figures 26 and 27 show the relative permeability and fractional flow for S-601 core sample by GWLI. According to the relative permeability curve from intersection point curves, the wettability of S-604 is water wet. From figure 27, the actual water saturation breakthrough is $73.14 \%$, the breakthrough occurs when the water saturation at breakthrough and the fractional flow at breakthrough occur in the beginning the GWLI.

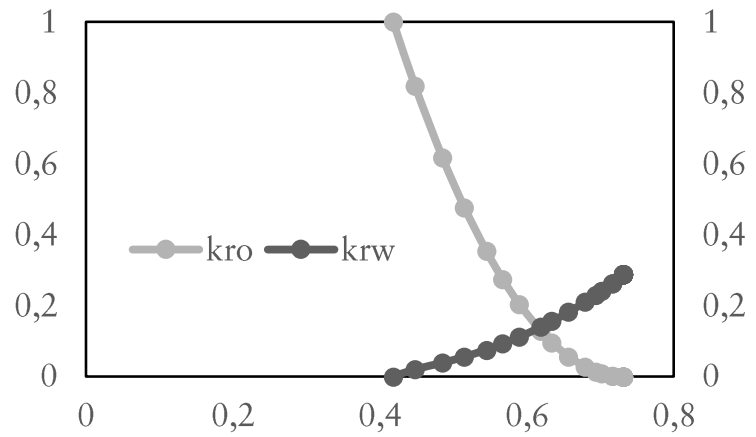

Figure 26 Relative permeability for S-604 core sample

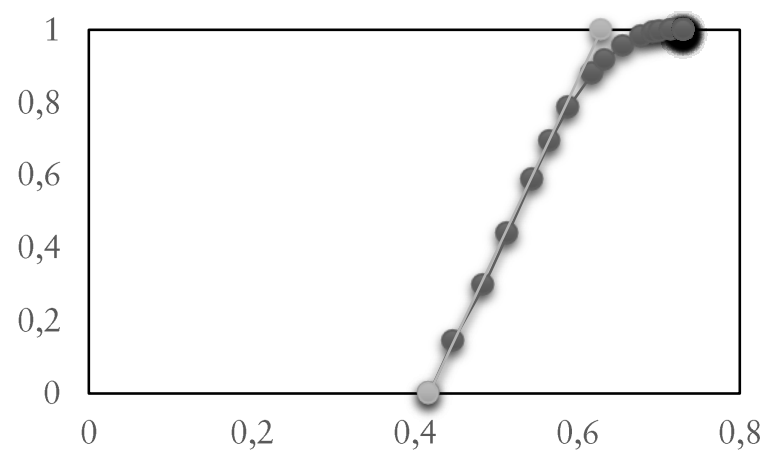

Figure 27 Fractional flow for S-604 core sample

Table 5 Recovery Factor Result for Gaberoun Water Injection at pH 5 and pH 10

\begin{tabular}{cccc}
\hline \multicolumn{2}{c}{ GWLI at pH 5 } & \multicolumn{2}{c}{ GWLI at $\mathrm{pH} \mathrm{10}$} \\
\hline Core No & Recovery factor (Frac) & Core No & Recovery factor (Frac) \\
\hline S-101 & 0.67 & S-601 & 0.42 \\
\hline S-400 & 0.46 & S-603 & 0.45 \\
\hline S-600 & 0.54 & S-604 & 0.53 \\
\hline
\end{tabular}

In this study, the absolute permeability and porosity of the sandstone and carbonate cores, have a significant effect on the oil recovery. The oil recovery increased with increasing the permeability and porosity of the core. For example, core S-101, this core has high porosity and permeability which give high oil recovery. The impact of acidity $(\mathrm{pH})$ of GWLI on oil recovery in sandstone and carbonate core samples was higher with $\mathrm{pH}$ is 5 than when the acidity is 10 . Table 5 and Figure 28 shows the recovery factors for core samples that injected by GWLI at $\mathrm{pH} 5$ and $\mathrm{pH} 10$.

The impact of GWLI on oil recovery in sandstone core samples was higher than carbonate core samples. The effect the wettability on oil recovery has also been observed. The cores with water-wet state has showed a better oil recovery comparing with cores with oil-wet state and mixed-wet state. For example, this case happened in core with mixed-wet (S-601) gave oil recovery is $42.22 \%$, while in core water-wet (S-101) gave oil recovery is $67.27 \%$.

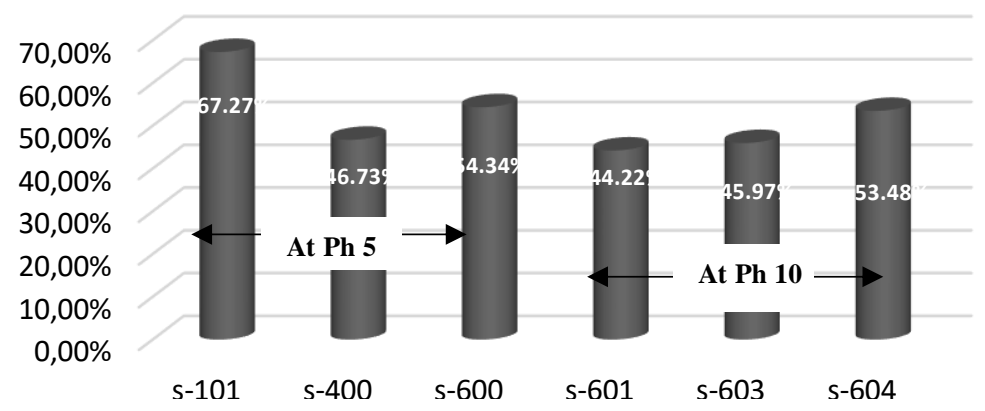

Figure 28 The recovery factors for core samples that injected by GWLI at $\mathrm{pH} 5$ and $\mathrm{pH} 10$ 


\section{CONCLUSIONS}

In this study, a Gaberoun Water Leak Injection (GWLI) has been discovered and investigated as a new Libyan chemical EOR in laboratories on relative permeability, wettability, oil recovery, breakthrough, and fractional flow for carbonate and sandstone reservoirs. Because the case studied involves only one dead oil, at constant temperature, and pressure, the results and conclusions may not be scientifically adequate for general meanings.

\section{CURRENT AND FUTURE WORK}

The GWLI has resulted in effects on relative permeability, wettability, oil recovery, breakthrough and fractional flow. Therefore, it is very important to evaluate the effects of GWLI in carbonate reservoirs. In order to achieve that, this research is currently ongoing and being expanded in the following designated directions:

- GWLI is being continued with different live oil samples at elevated pressure and temperature at reservoir condition.

- Future work, assessment of the effects of acidity and the different salinity of GWLI on oil recovery during/after GWLI will also be conducted.

\section{REFERENCES}

Al-Shalabi, E. W., Sepehrnoori, K., Delshad, M., \& Pope, G. (2015). A novel method to model lowsalinity-water injection in carbonate oil reservoirs. SPE Journal, 20(5), 1154-1166. https://doi.org/10.2118/169674-PA

Al-Shalabi, E. W., Sepehrnoori, K., \& Pope, G. (2015). Geochemical interpretation of low-salinity-water injection in carbonate oil reservoirs. SPE Journal, 20(6), 1212-1226. https://doi.org/10.2118/169101-PA

Alotaibi, M. B., Nasralla, R. A., \& Nasr-El-Din, H. A. (2011). Wettability studies using low-salinity water in sandstone reservoirs. SPE Reservoir Evaluation and Engineering, 14(6), 713-725. https://doi.org/10.2118/149942-PA

Austad, T., Rezaeidoust, A., \& Puntervold, T. (2010). Chemical Mechanism of Low Salinity Water Flooding in Sandstone Reservoirs. SPE Improved Oil Recovery Symposium. https://doi.org/10.2118/129767-MS

Austad, T., Strand, S., Madland, M. V., Puntervold, T., \& Korsnes, R. I. (2008). Seawater in chalk: An EOR and compaction fluid. SPE Reservoir Evaluation \& Engineering, 11(04), 648-654. https://doi.org/10.2118/118431-pa

Banks, E., Batelaan, O., Cahill, K., Cook, P., Dean, W., Ellis, J., ... Post, V. (2015). Use of geophysics to support water security and increase community awareness on Milingimbi Island, northern Australia. SEG Technical Program Expanded Abstracts, 34, 4963-4967. https://doi.org/10.1190/segam20155899742.1

Baruah, B. M., \& Chan, K. S. (2014). Water injection in brown field: Never too late. Proceedings of the Annual Offshore Technology Conference, 3, 2002-2013. https://doi.org/10.4043/24906-ms

Hidayat, F., Erfando, T., \& Maulana, B. F. (2018). Spontaneous Imbibition Test of Low Salinity Injection at Low Saline Waxy Crude Carbonate. Journal of Earth Energy Engineering, 7(2), 14-22. https://doi.org/10.25299/jeee.2018.vol7(2).2215

Law, S., Sutcliffe, P., \& Fellows, S. (2014). Secondary application of low salinity waterflooding to forties sandstone reservoirs. SPE Annual Technical Conference and Exhibition, 3, 2006-2021. https://doi.org/10.2118/170725-ms

Martinez, V., \& Ascendo, F. (2018). A new practical water injection system in offshore fields. Proceedings of the Annual Offshore Technology Conference, 3, 1761-1769. https://doi.org/10.4043/28741-ms

McCune, C. C. (1982). SEAWATER INJECTION EXPERIENCE - AN OVERVIEW. Journal of Petroleum Technology, 34(10), 2265-2270. https://doi.org/10.2118/9630-pa

Naser, M. A. (2016). A laboratory investigation of the effects of temperature, hardness, surfactants and alkaline on oil recovery from carbonate reservoirs using spontaneous imbibition tests - Semantic Scholar. Journal of Fundamentals of Renewable Energy and Applications, 6(5). Retrieved from 
https://www.semanticscholar.org/paper/A-laboratory-investigation-of-the-effects-of-and-onNaser/8f5e0f3ba448ad9a0cb126590331e2fc36d1b161

Ngansom, W., \& Dürrast, H. (2016). Saline hot spring in Krabi, Thailand: A unique geothermal system OnePetro. SEG International Exposition and Annual Meeting. Retrieved from https://www.onepetro.org/conference-paper/SEG-2016-13880715

Ramanathan, R., Shehata, A. M., \& Nasr-El-Din, H. A. (2015). Water alternating CO 2 injection process - Does modifying the salinity of injected brine improve oil recovery? Offshore Technology Conference Brasil The Atlantic: From East to West - An Ocean of Innovation, 1666-1692. https://doi.org/10.4043/26253-ms

Romanuka, J., Hofman, J. P., Ligthelm, D. J., Suijkerbuijk, B. M. J. M., Marcelis, A. H. M., Oedai, S., ... Austad, T. (2012). Low salinity EOR in carbonates. SPE Improved Oil Recovery Symposium, 1, 169-184. https://doi.org/10.2118/153869-ms

Schiozer, D. J., \& Mezzomo, C. C. (2003). Methodology for Field Development Optimization with Water Injection. SPE Hydrocarbon Economics and Evaluation Symposium. https://doi.org/10.2118/82021MS

Shehata, A. M., Alotaibi, M. B., \& Nasr-El-Din, H. A. (2014). Waterflooding in carbonate reservoirs: Does the salinity matter. SPE Reservoir Evaluation and Engineering, 17(3), 304-313. https://doi.org/10.2118/170254-PA

Shehata, Ahmed M., \& Nasr-El-din, H. A. (2017). Laboratory investigations to determine the effect of connate-water composition on low-salinity waterflooding in sandstone reservoirs. SPE Reservoir Evaluation and Engineering, 20(1), 59-76. https://doi.org/10.2118/171690-pa

Sheng, J. J. (2011). Modern Chemical Enhanced Oil Recovery (1st ed.). Oxford: Gulf Professional Publishing.

Siso, S., Awni, I., Solyman, M., \& Ibrahim, T. (2017). Water Injection Strategy in Belayim Fields. Offshore Mediterranean Conference and Exhibition. Ravenna, Italy: Offshore Mediterranean Conference. 